\title{
Effects of $\alpha$-noradrenergic substances on the optokinetic and vestibulo-ocular responses in the rabbit: a study with systemic and intrafloccular injections
}

\author{
H.S. $\operatorname{Tan}^{1}$, J. van Neerven ${ }^{1}$, H. Collewijn ${ }^{1}$ and O. Pompeiano ${ }^{2}$ \\ 'Department of Physiology I, Faculty of Medicine, Erasmus University Rotterdam, Rotterdam (The Netherlands) and ${ }^{2}$ Department of \\ Physiology and Biochemistry, University of Pisa, Pisa (Italy)
}

(Accepted 28 May 1991)

Key words: $\alpha$-Noradrenergic effect; Vestibulo-ocular reflex; Optokinetic reflex; Cerebellum; Flocculus; Clonidine

\begin{abstract}
The effects of microinjection of $\alpha$-noradrenergic agonists and antagonists in the flocculus on the basic gain and adaptibility of vestibuloocular and optokinetic responses were investigated. A complementary, previous investigation ${ }^{46}$ had shown that the adaptation, but not the basic performance, of compensatory oculomotor responses were markedly influenced by $\beta$-noradrenergic mechanisms in the flocculus. In contrast, the present experiments with bilateral, intrafloccular injections of phenylephrine, prazosin, clonidine and idazoxan failed to reveal any effect of $\alpha_{1}$ - or $\alpha_{2}$-noradrenergic mechanisms on either basic performance or adaptation of compensatory eye movements. Intravenous administration of clonidine, however, reduced the gain of the optokinetic and vestibulo-ocular responses by about 70 and $50 \%$, respectively, at dosages of $0.07 \mathrm{mg} / \mathrm{kg}$. Recovery from this effect took about $1.5 \mathrm{~h}$. A higher dosage of clonidine $(0.7 \mathrm{mg} / \mathrm{kg}) \mathrm{had}$ a similar, but longer lasting effect, and also markedly increased the frequency of spontaneous saccades. Intravenous administration of phenylephrine did not affect the oculomotor responses. It is concluded that the control of oculomotor responses is not susceptible to $\alpha$-noradrenergic influences at the level of the flocculus, but that $\alpha_{2}$-agonistic action inhibits these responses through an extra-floccular structure.
\end{abstract}

\section{INTRODUCTION}

Noradrenergic terminals, derived to a large extent from neurons in the locus coeruleus (LC), are distributed throughout the entire central nervous system ${ }^{2,10}$. With regard to their possible function, one hypothesis states that the noradrenergic system exerts a modulatory action, possibly increasing the signal-to-noise ratio of evoked versus spontaneous activity of the various target neurons ${ }^{11,28.48,49}$ and/or gating the efficacy of subliminal synaptic inputs conveyed by classical afferent systems ${ }^{26}$, 56. A second hypothesis states that noradrenaline (NA) is involved in a number of plasticity-related functions ${ }^{18,19,21}$.

A thoroughly studied model of neural plasticity is the adaptability of the vestibulo-ocular reflex (VOR) to modified functional demands (for a review see ref. 25). A general role of NA in plasticity of the VOR has been demonstrated previously in the cat ${ }^{20,24}$. In these studies, depletion of the central stores of NA by intracisternal injection of 6-hydroxydopamine (6-OHDA) abolished the ability to produce adaptive changes in the VOR gain. The cerebellar flocculus has been implicated in the con- trol of the gains of the VOR and optokinetic response (OKR) and their adaptive changes. Removal of the flocculus abolishes the adaptability of the VOR in rabbits $^{16,30}$ and cats ${ }^{38}$ while reversible blocking of floccular neurons by local injection of GABA-agonists strongly reduces the basic gains of the VOR and OKR ${ }^{45}$. Heterosynaptic, plastic interaction between the signals carried by the floccular climbing and parallel fibers has been postulated as the substrate of cerebellar motor adaptability and learning (for reviews see refs. 14,15).

In the framework of this theory, the demonstrated effect of NA depletion on VOR adaptation might be due to disruption of the NA input to the flocculus. This latter hypothesis has recently been supported by Van Neerven et al. ${ }^{46}$, who showed that local injection of the $\beta$-adrenergic agonist isoproterenol into the cerebellar flocculi improved the adaptation of the VOR, while injection of the $\beta$-antagonist sotalol impaired adaptation, while these drugs did not affect the gain of the VOR in the absence of pressure for adaptation. These results are in good harmony with earlier findings ${ }^{26-29,47,57}$ that the increased responsiveness of cerebellar Purkinje cells to

Correspondence: H. Collewijn, Department of Physiology I, Faculty of Medicine, Erasmus University Rotterdam, P.O. Box 1738, NL-3000 DR Rotterdam, The Netherlands. Fax (31) (10) 4367594. 
both excitatory (mossy fibers and climbing fibers) and inhibitory (basket and stellate cells) inputs, as well as to the corresponding excitatory (glutamate and aspartate) and inhibitory (GABA) neurotransmitters following local application of NA or LC stimulation was mediated by $\beta$-receptors. However, $\alpha$-receptors have also been demonstrated in the cerebellum ${ }^{5}$, although their density is comparatively low. Both the $\alpha_{1}$ and the $\alpha_{2}$ subtypes appear to be present. In the rat, fairly large numbers of $\alpha_{1}$-receptors were found in the molecular layer, but not in the granular layer, of the cerebellar cortex ${ }^{17,31}$. In contrast, low, but specific, labeling for $\alpha_{2}$-receptors was reported for the granular layer ${ }^{4.43}$, while another recent study mentions moderately dense labeling of the Purkinje cell layer ${ }^{3}$. Sagittal strips of $\alpha_{2}$-receptors were found specifically in the molecular layer of vermal lobules 9 and 10 (ref. 4). As the number of $\alpha_{1}$-receptors in the cerebellum could be either down- or up-regulated by decreasing or increasing the NA levels in the brain, the $\alpha_{1}$-receptors at cerebellar NA synapses seem to be of functional significance ${ }^{44}$, although this function remains to be elucidated. The $\alpha_{2}$-receptors were originally defined in the peripheral autonomic nervous system in terms of their capacity to modulate NA release by autoinhibition; they are supposed to occur in presynaptic terminal membranes ${ }^{39}$. In the central nervous system, it appears that $\alpha_{2}$-binding sites may be localized either preor postsynaptically ${ }^{43}$. A recent electrophysiological study $^{32}$ supports a role of $\alpha$-, as well as $\beta$-receptors in the noradrenergic effects on Purkinje cells.

Systemically injected $\alpha$-agonists have been shown to induce an inhibition of LC neuron activity ${ }^{37,40}$. Moreover, microiontophoretically applied clonidine powerfully inhibits the discharge of LC neurons and the release of NA from nerve terminals ${ }^{10}$, as shown also in the behaving cat ${ }^{1}$. In view of the finding that activation of the $\alpha_{2}$-receptors by microinjections of clonidine into the $\mathrm{LC}$ affects the gain of vestibulospinal reflexes ${ }^{33,34}$, we first investigated the effect of general stimulation of $\alpha$-receptors by the systemic injection of $\alpha$-agonists on the VOR and OKR gain. Marked reductions of these gains were induced by the injection of the $\alpha_{2}$-agonist clonidine.

Subsequently, we investigated these effects at the cerebellar level by bilateral floccular injection of $\alpha_{1^{-}}$and $\alpha_{2}$-agonists and antagonists. In view of the crucial role of the flocculus in the control of the VOR and OKR, this might be a sensitive test of the functionality of $\alpha$-receptors in the cerebellar cortex. Such function could not be demonstrated: neither the basic performance, nor the adaptive gain changes of the VOR and OKR were affected by these procedures. Apparently, the primary site of action of systemically injected clonidine in reducing the VOR and OKR is outside the flocculus.

\section{MATERIALS AND METHODS}

General

The experiments were done on a total number of 25 young adult, pigmented Dutch belted rabbits of either sex. All surgical procedures were done under general anesthesia induced by ketamine (Nimatek, $100 \mathrm{mg} / \mathrm{ml}$, AUV, Holland), acepromazine 1\% (Vetranquil, $10 \mathrm{mg} / \mathrm{ml}$, Sanof, France) and xylazine-HCl (Rompun $2 \%$. $22.3 \mathrm{mg} / \mathrm{ml}$, Bayer, F.R.G.). Initial doses of $0.7 \mathrm{mg} / \mathrm{kg}$ of a mixture of ketamine and acepromazine (in $10: 1$ proportion by volume) and, in a separate injection, $0.25 \mathrm{ml} / \mathrm{kg}$ of xylazine- $\mathrm{HCl}$ were given intramuscularly. These initial doses, which maintained a good anesthesia for about $1 \mathrm{~h}$, were supplemented as necessary

\section{Measurement of eye movements}

Eye movements were measured with a magnetic induction method with ocular sensor coils in a rotating magnetic field, based on phase detection ${ }^{6}$. A major advantage of this method is the absolute angular calibration of the recordings. The rabbits were permanently implanted with scleral search coils and skull screws for fixation of the head. A coil of 5 turns of teflon-coated stainless steel wire (type AS 632, Cooner, Chatsworth, CA) was woven underneath the conjunctiva and the superior and inferior rectus eye muscles.

\section{Implantation of guide cannulae}

About a week after the implantation of the scleral coil, guide cannulae were implanted under general anesthesia. The focculus was localized by electrophysiological recordings, using a glass micropipette with a $4 \mu \mathrm{m}$ tip, filled with $2.0 \mathrm{M} \mathrm{NaCl}$. Floccular Purkinje cells were identified by the modulation of their complex spike activity, synchronous with horizontal movements of a random-dot pattern in front of the animal's ipsitateral eye ${ }^{13}$. Once the appropriate location was found, the guide cannula, which surrounded the micropipette, was fixed to the skull, without penetrating the brain. to establish the direction for future drug injection cannulas. The depth of the micropipette relative to the guide cannula was marked to establish the appropriate length of the injection cannulae ${ }^{45,46}$.

\section{Injected drugs}

Floccular injections were made with the $\alpha_{1}$-agonist phenylephrine-HCl (Sigma, U.S.A.; $16 \mu \mathrm{g} / \mu \mathrm{l}$ ); the $\alpha_{1}$-antagonist prazosin (Pfizer, Belgium; $4 \mu \mathrm{g} / \mu \mathrm{l}$ ), the $a_{2}$-agonist clonidine (Sigma, U.S.A.; $4 \mu \mathrm{g} / \mu \mathrm{l}$ ) and the $\alpha_{2}$-antagonist idazoxan (Reckitt and Colman, U.K.; $8 \mu \mathrm{g} / \mu \mathrm{l}$ ). Each substance was dissolved in saline and adjusted to $\mathrm{pH} \mathrm{7.0-7.4.} \mathrm{The} \mathrm{solutions} \mathrm{were} \mathrm{injected} \mathrm{through} \mathrm{a} \mathrm{stainless} \mathrm{steel}$ injection cannula (o.d. $0.35 \mathrm{~mm}$ ) of the proper, predetermined length, which was introduced through the guide cannula and connected to a Hamilton $1.0 \mu \mathrm{l}$ syringe. In the control experiments; only the solvent (saline) was injected. All floccular injections were made bilaterally.

In the experiments with systemic, intravenous drug injections, we used phenylephrine $(0.7 \mathrm{mg} / \mathrm{kg})$ and clonidine $(0.007,0.07$ and 0.7 $\mathrm{mg} / \mathrm{kg}$ ), dissolved in saline.

\section{Procedure for systemic injections, without adaptation}

These experiments were done to explore the general effeets of systemic, intravenous injections of $\alpha$-adrenergic agonists on the basic performance of the VOR and OKR. Two groups of 5 rabbits (separate from the animals in which we performed intrafloccular injections) were used for the two agonists. The group in which the effects of phenylephrine were tested was also subjected to a control experiment with injection of saline, while in the clonidine group the effect of 3 different doses of clonidine was investigated.

During each experiment, the rabbit was restrained in a linen bag and tied down on a platform. The head was connected to a frame which was attached to the platform, but did not intrude into the rabbit's visual field. The platform on which the rabbit was inounted was surrounded by a concentric, richly patterned drum which was moved to elicit the OKR. The rabbits were oscillated sinusoidally 
on the platform at a frequency of $0.15 \mathrm{~Hz}$ and an amplitude of $5^{\circ}$ in light or darkness to elicit the VOR in light and darkness, respectively. To elicit the OKR, the drum was oscillated at the same frequency and amplitude. The drum or the platform did move only during the measurements and not continuously, to avoid adaptation. In each measurement period, the VOR in the light and in darkness, as well as in the OKR were recorded.

After the measurement of 3 baseline values the drug was injected. Subsequently, 4 measurements were made with an interval of $5 \mathrm{~min}$, followed by 9 further measurements with an interval of $15 \mathrm{~min}$

Procedures for floccular injection, without adaptation

These experiments tested whether $\alpha$-adrenergic substances, injected into the flocculus, affect the basic characteristics of the VOR or OKR. Three sessions were run on each rabbit to determine the time course of: (1) changes in the VOR and OKR without any injection; (2) changes in the VOR and OKR gain after injection of the appropriate agonist; and (3) changes in the VOR and OKR gain after injection of the appropriate antagonist. In all cases, 1.0 $\mu \mathrm{l}$ of the solution was injected bilaterally in the flocculus. The sequence of these treatments was randomized. There was always a recovery period of at least 1 day between successive experiments. The stimulus parameters were identical to those described for the systemic injections.

\section{Procedure for adaptation}

In these experiments the effects of $a$-adrenergic drugs, injected bilaterally into the flocculus, on adaptation of the VOR and OKR were tested. Adaptive enhancement of the VOR gain was elicited by sinusoidally oscillating the platform with a frequency of $0.15 \mathrm{~Hz}$ and an amplitude of $5^{\circ}$. while the optokinetic drum moved in counterphase at the same frequency but with an amplitude of $2.5^{\circ}$ (ref. 46). This stimulus, which increased the ideal value of compensatory cye movements from 1.0 to 1.5 , was continuously presented for $3 \mathrm{~h}$. It reliably induced an adaptive increase in the VOR gain in light as well as in darkness.

Each experiment started with 4 baseline measurements of the VOR during platform oscillation in light, as well as in darkness. During these 8 baseline measurements, which together took about $15 \mathrm{~min}$, the platform was oscillated while the drum remained stationary. The platform did not move in between the baseline measurements. Once the latter were completed, bilateral injections of the various drugs were made and motion of both the platform and the drum in counterphase was started. The next measurement was made as soon as possible after the injection. During the rest of the experiment, recordings of the VOR in light and in darkness were taken every $15 \mathrm{~min}$. Each recording took about $90 \mathrm{~s}$. In this way, the adaptive process was continuous over successive periods of 13.5 $\mathrm{min}$, and interrupted only for $1.5 \mathrm{~min}$ for recording. This short interruption did not noticeably affect the adaptive process.

In cach rabbit, the experiment described above was performed in 3 conditions: (1) a control adaptation without any injection; (2) an adaptation after injection of the appropriate agonist; and (3) an adaptation after injection of the appropriate antagonist. These 3 sessions were performed in a random order. There was always at least 1 day of rest between two sessions, to allow the rabbit to recover fully from the previous experiment.

\section{Data storage and analysis}

All experiments were computer driven (Digital Equipment Corporation, PDP 11/73). The data were gathered by a data acquisition program, collecting 4 cycles of the sinusoidal motion stimulus and response for each response type at a sample frequency of 102.4 $\mathrm{Hz}$. In subsequent off-line analysis the fast phases of the eye movement response were eliminated from the record, and then gain and phase of the responses were determined after a fast Fourier transformation.

The effects of the injected substances were tested for statistical significance with a Multiple Analysis of Variance (MANOVA), a test which allows the comparison of several variables in a single group of animals.

At the end of the last experiment, each rabbit that had undergone intrafloccular injections was injected with a dye (Pontamine sky blue or ink) through the same injection cannula used in the previous injections. The animal was then deeply anesthetized and perfused from the left cardiac ventricle with saline and $10 \%$ formalin. After sectioning and staining of the brainstem and cerebellum, the injection site could be visualized. In all cases, its floccular location was verified.

\section{RESULTS}

\section{Systemic injection of clonidine}

In 5 rabbits, changes in the gain of the VOR in light,

\section{Clonidine i.v. $\quad n=5$}
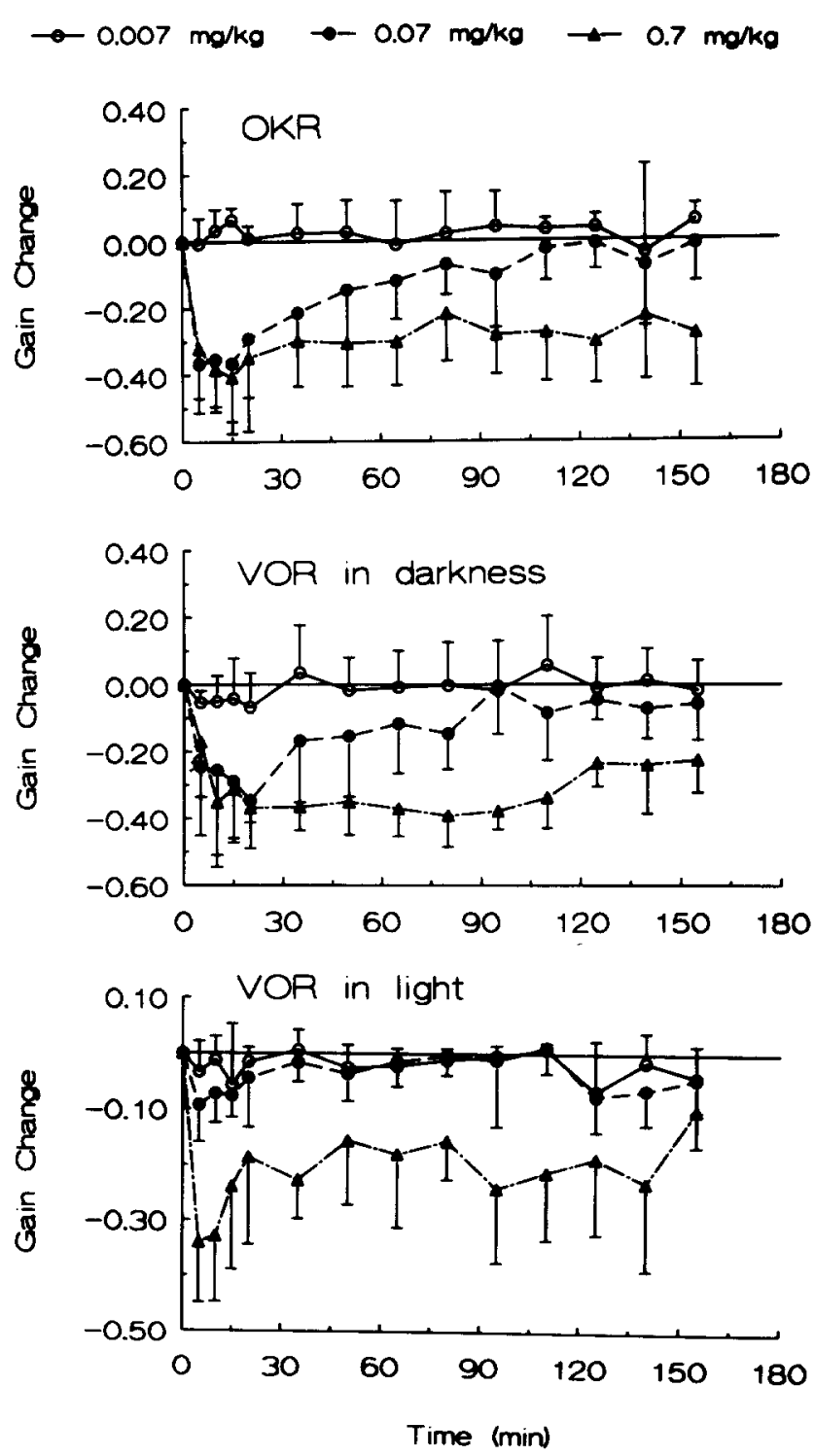

Fig. 1. Mean effects of 3 different intravenous doses of clonidine at time $=0$ on the gains of the OKR and VOR in darkness and light. Bars represent 1 S.D. Baseline gains before the injection are normalized to zero. 


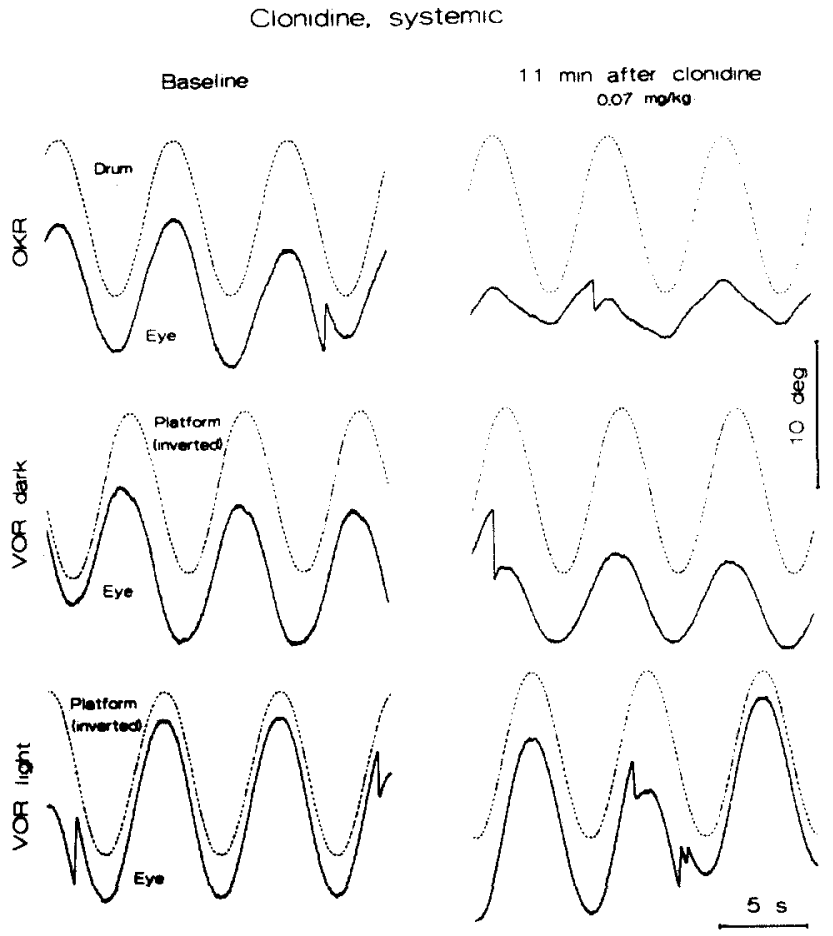

Fig. 2. Recordings from one representative session showing oculomotor responses before, and $\mathbf{1 1} \mathrm{min}$ after, intravenous injection of $0.07 \mathrm{mg} / \mathrm{kg}$ clonidine. Note the marked reduction in amplitude of the OKR and VOR in darkness.

the VOR in darkness and the OKR were assessed during $3 \mathrm{~h}$ after intravenous injection of the $\alpha_{2}$-agonist clonidine. Each animal underwent 3 experimental sessions, in which 3 different dosages of clonidine were given, in random order. The mean baseline gains were $1.05 \pm$ 0.05 (S.D.) for the VOR in light, $0.82 \pm 0.14$ for the VOR in darkness and $0.57 \pm 0.24$ for the OKR. These baseline gains remained virtually constant during the complete series of experiments. The averaged results are shown in Fig. 1.

Clonidine in the lowest dosage $(0.007 \mathrm{mg} / \mathrm{kg})$ did not affect any of the examined reflexes. After a clonidine dosage of $0.07 \mathrm{mg} / \mathrm{kg}$, however, the gains of both the VOR in darkness and the OKR decreased sharply, by about 0.4 with respect to the baseline values, in all of the rabbits tested. This decrease was apparent immediately after the injection, and reached its maximum about 5-10 min later. Typical recordings of the OKR and VOR in darkness and in light before and 11 min after intravenous injection of $0.07 \mathrm{mg}$ clonidine are shown in Fig. 2. The reduction of the gain by an absolute decrease of about 0.4 actually amounted to a relative decrease in VOR gain to about half of the baseline value, and a relative decrease in OKR gain to about one third of the baseline value. After about $20 \mathrm{~min}$ the gains of VOR in darkness and OKR started to recover. Normal values were regained after about $1.5 \mathrm{~h}$. In contrast, the VOR

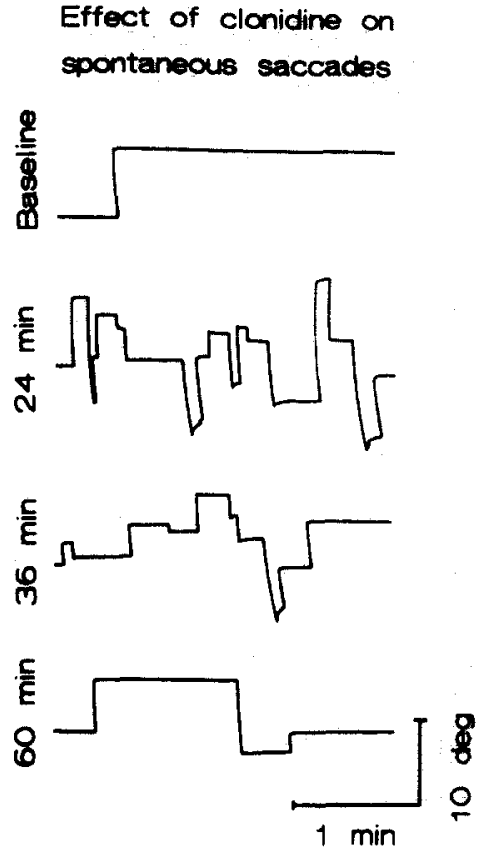

Fig. 3. Recordings showing the increase in frequency of spontaneous saccades occurring after intravenous injection of $0.7 \mathrm{mg} / \mathrm{kg}$ clonidine, lasting for about $1 \mathrm{~h}$.

in light was only slightly affected by this clonidine dosage.

Injection of clonidine at the highest dosage $(0.7 \mathrm{mg} /$ $\mathrm{kg}$ ) had quantitatively the same initial effect as the dosage of $0.07 \mathrm{mg} / \mathrm{kg}$ on the VOR in darkness and the OKR, causing gain reductions by about 0.4 with respect to the baseline values. This suggests a saturation of the suppressive effect. The duration of the suppression was, however, much prolonged after this high dosage, and gain values did not return towards normal within the $3 \mathrm{~h}$ of measurement. On the next day the original baseline values were re-obtained, which ruled out a permanent effect of clonidine at this high concentration. The high dosage of clonidine also caused a distinct decrease in the gain of the VOR in light, by about 0.3 .

Strikingly, immediately after injection of the $0.7 \mathrm{mg} / \mathrm{kg}$ clonidine dosage, frequent spontaneous saccades appeared, and remained present until 30-60 min after the injections (Fig. 3). Such spontaneous saccades are normally rare in rabbits with the head fixed ${ }^{7}$ and they did not appear after the two lower dosages of clonidine. Statistical analysis showed that the effects of clonidine on the VOR in light, VOR in darkness and OKR were highly significantly dose-dependent $(P=0.001, P=$ 0.001 , and $P=0.002$, respectively).

In two rabbits, a control experiment was carried out with intravenous injection of $1 \mathrm{ml}$ saline. This did not cause a change in any of the reflexes in any case. This result was identical to that after the lowest dosage of clonidine. These negative results and the dosage-re- 
sponse relation prove that the decreases in gain were specific for clonidine, and not related to the stress of undergoing an intravenous injection. Changes in the animal's behavior were not apparent after any of the dosages of clonidine, but our observations in this respect are limited by the fact that the rabbits were tied down. By the time the animals were released, they showed a normal posture and locomotion, but no formal tests of the vigilance level were done. The appearance of spontaneous saccades and the relatively preserved gain of the VOR in light after the highest dosage of clonidine suggest that the decreases in gain of the OKR and VOR in darkness were not simply caused by sedation and drowsiness.

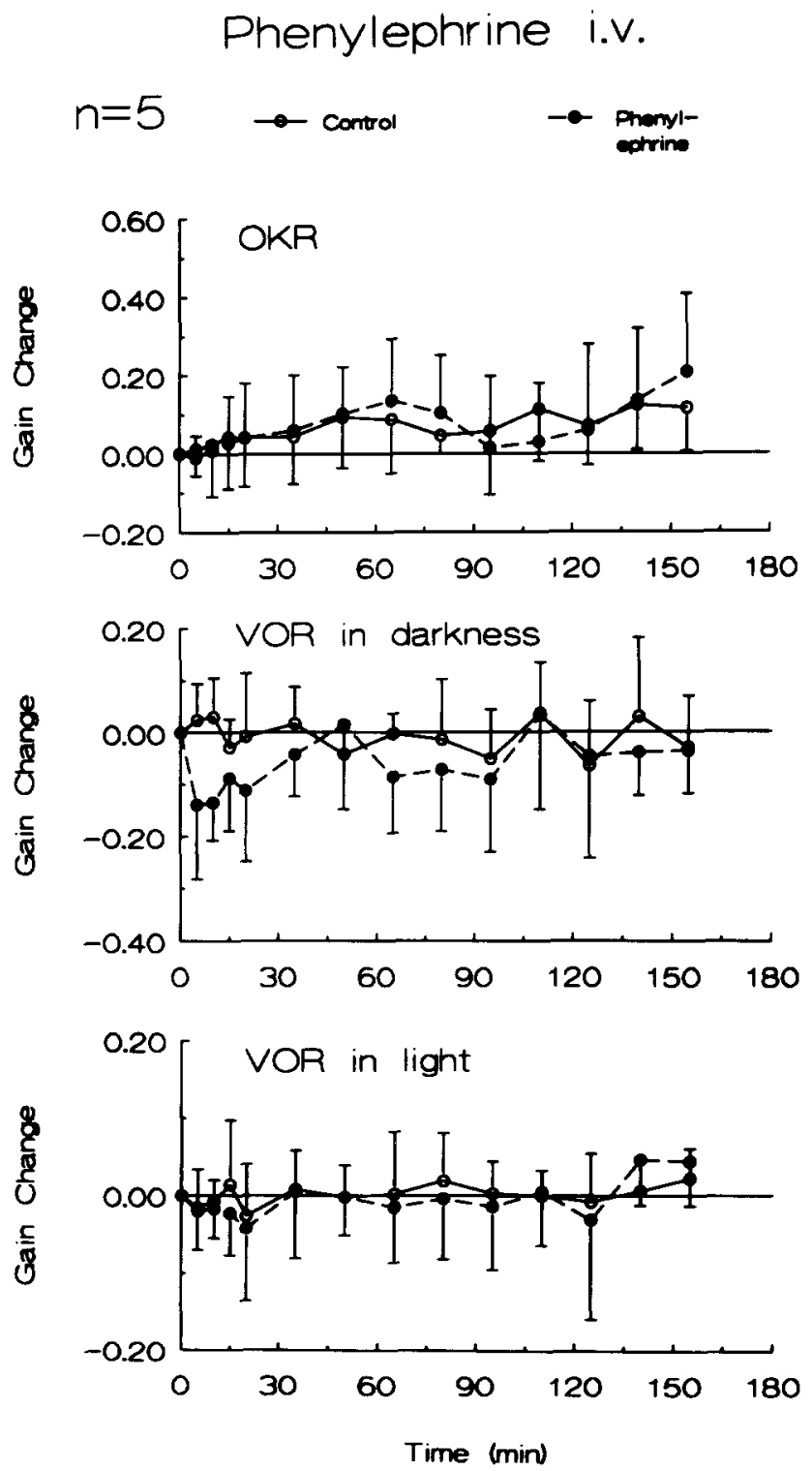

Fig. 4. Changes in gain of oculomotor responses as a function of time after intravenous injection of $0.7 \mathrm{mg} / \mathrm{kg}$ phenylephrine at time $=0$. Conventions as in Fig. 1 .

\section{Systemic injection of phenylephrine}

In 5 rabbits, the time course of the gain of the VOR in light and in darkness, and the OKR was tested during $3 \mathrm{~h}$ after the intravenous injection of the selective $\alpha_{1}$-agonist phenylephrine $(0.7 \mathrm{mg} / \mathrm{kg})$, without pressure for adaptation. The mean baseline gains were $1.00 \pm 0.09$ (S.D.) for the VOR in light, $0.68 \pm 0.18$ for the VOR in darkness, and $0.41 \pm 0.11$ for the OKR. During the testing period, the VOR in light did not show any systematic variations in gain, either in the control experiments, or in the phenylephrine-injected experiments (Fig. 4). Statistical effects of the drug were absent for this condition $(P=0.876)$. In both control and phenylephrine-injected cases, the OKR showed a slight increase

$\alpha_{2}$-agents in flocculus Non-adaptation experiments

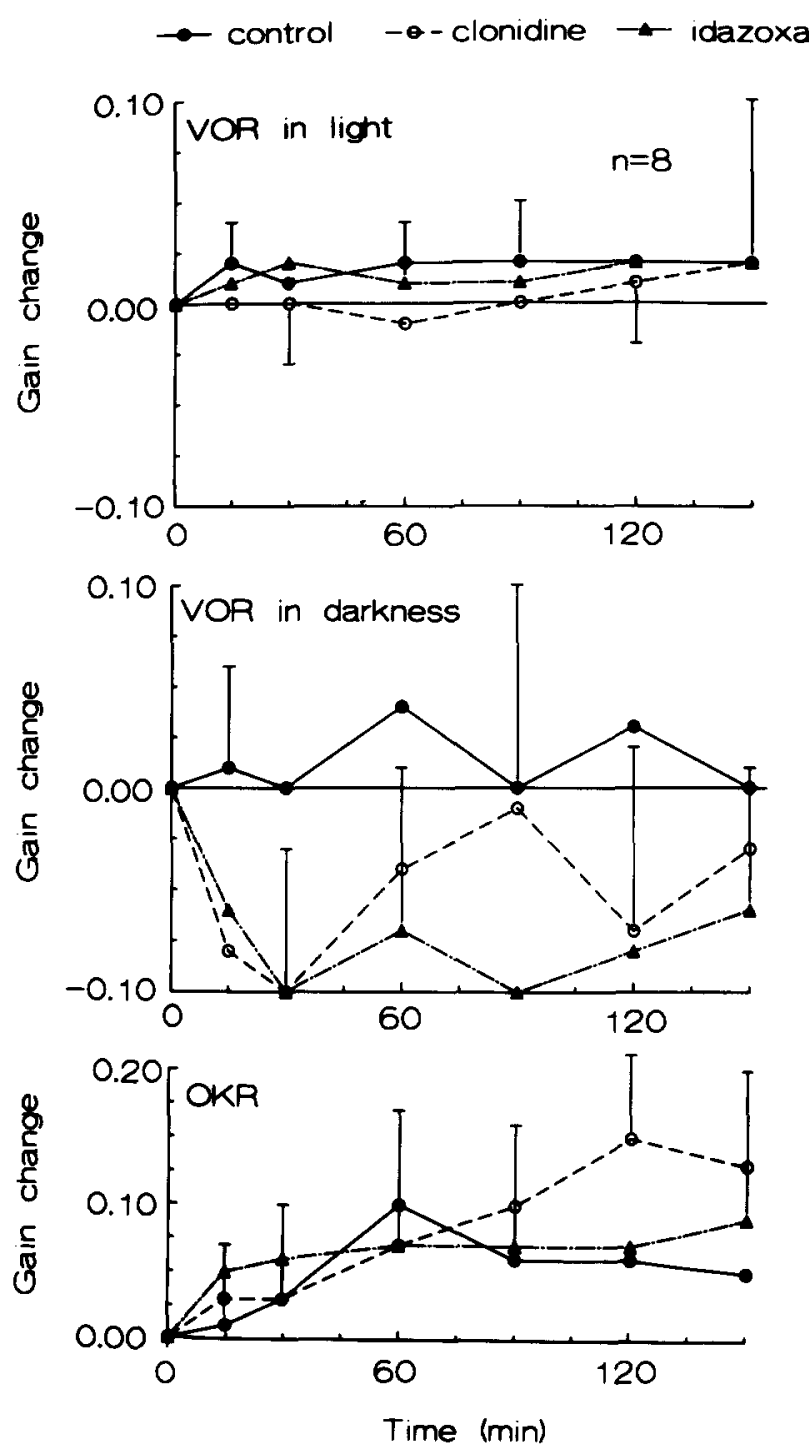

Fig. 5. Mean changes in gain (bars: 1 S.D.) of oculomotor responses as a function of time in control sessions and after bilateral injection in the flocculus of clonidine or idazoxan, without pressure for adaptation. 
in gain as a function of time; again the drug effect was not significant $(P=0.901)$. Phenylephrine administration did appear to result in an initial decrease in the gain of the VOR in darkness by about 0.15 with respect to the baseline values. This decrease lasted about $45 \mathrm{~min}$, after which the gain approached the control values. The effect did, however, not quite reach statistical significance $(P=0.083)$.

\section{Intrafloccular injections of $\alpha_{2}$-(ant)agonists}

In 6 rabbits, the time course of the gain of the VOR in light and in darkness, and the OKR, were tested without pressure for adaptation.

During the testing period, the VOR in light did not show any systematic changes in gain in the control experiments, nor after injection of clonidine or idazoxan (Fig. 5). The average gain of the VOR in darkness appeared to decrease, but this effect was statistically not significant. The average gain of the OKR showed a small increase over the period of $2.5 \mathrm{~h}$ in the control as well as in the injection experiments, as is often seen in nonadaptation experiments (see also Fig. 7). Neither clonidine nor idazoxan affected the OKR in a statistically significant way after injection in the flocculus, even though systemically administered clonidine reduced the gains of VOR and OKR markedly.

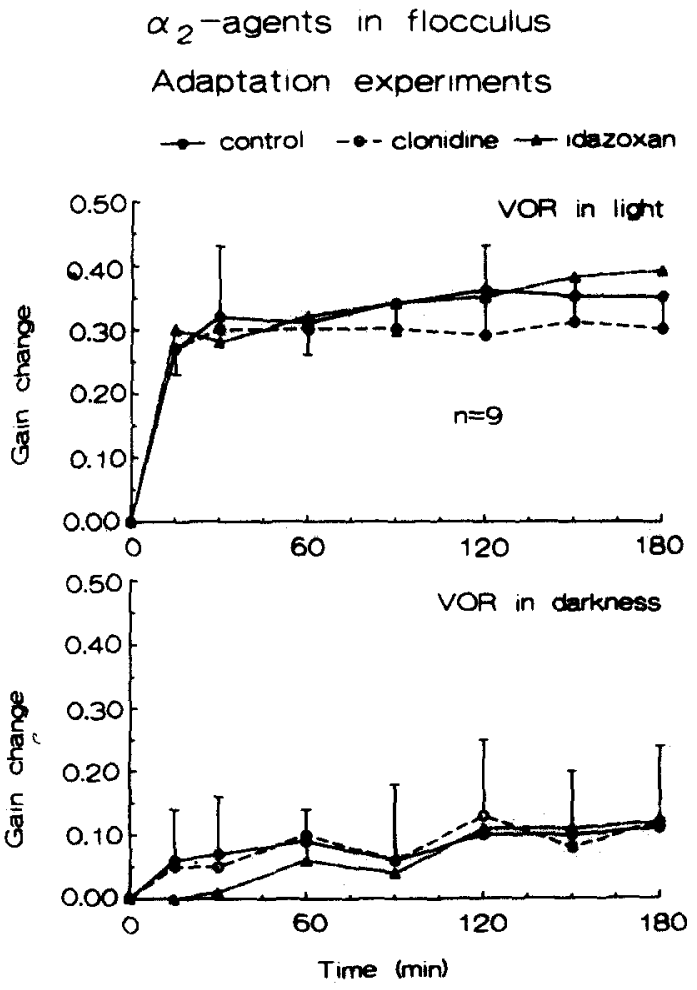

Fig. 6. Mean changes in gain of oculomotor responses under stimulus conditions requiring upward adaptation of the gain of the VOR (ideal value 1.5), in control sessions and after bilateral floccular injection of clonidine or idazoxan.
In the same 6 rabbits and in 3 others, the adaptibility of the VOR was also tested after intrafloccular injections of the same $\alpha_{2}$-adrenergic drugs. Adaptive gain change, measured during $3 \mathrm{~h}$, is shown in Fig. 6 for injection of clonidine and idazoxan, compared to the control adaptation experiment.

The adaptation of the VOR gain remained unaffected by the $\alpha_{2}$-noradrenergic substances, either in light or in darkness, as confirmed by analysis of variance.

In summary, intrafloccular injections of $\alpha_{2}$-noradrenergic substances did not have any statistically significant effects on the basic gains of the VOR and OKR or their adaptive changes.

$$
\alpha_{1} \text {-agents in flocculus }
$$

Non-adaptation experiments
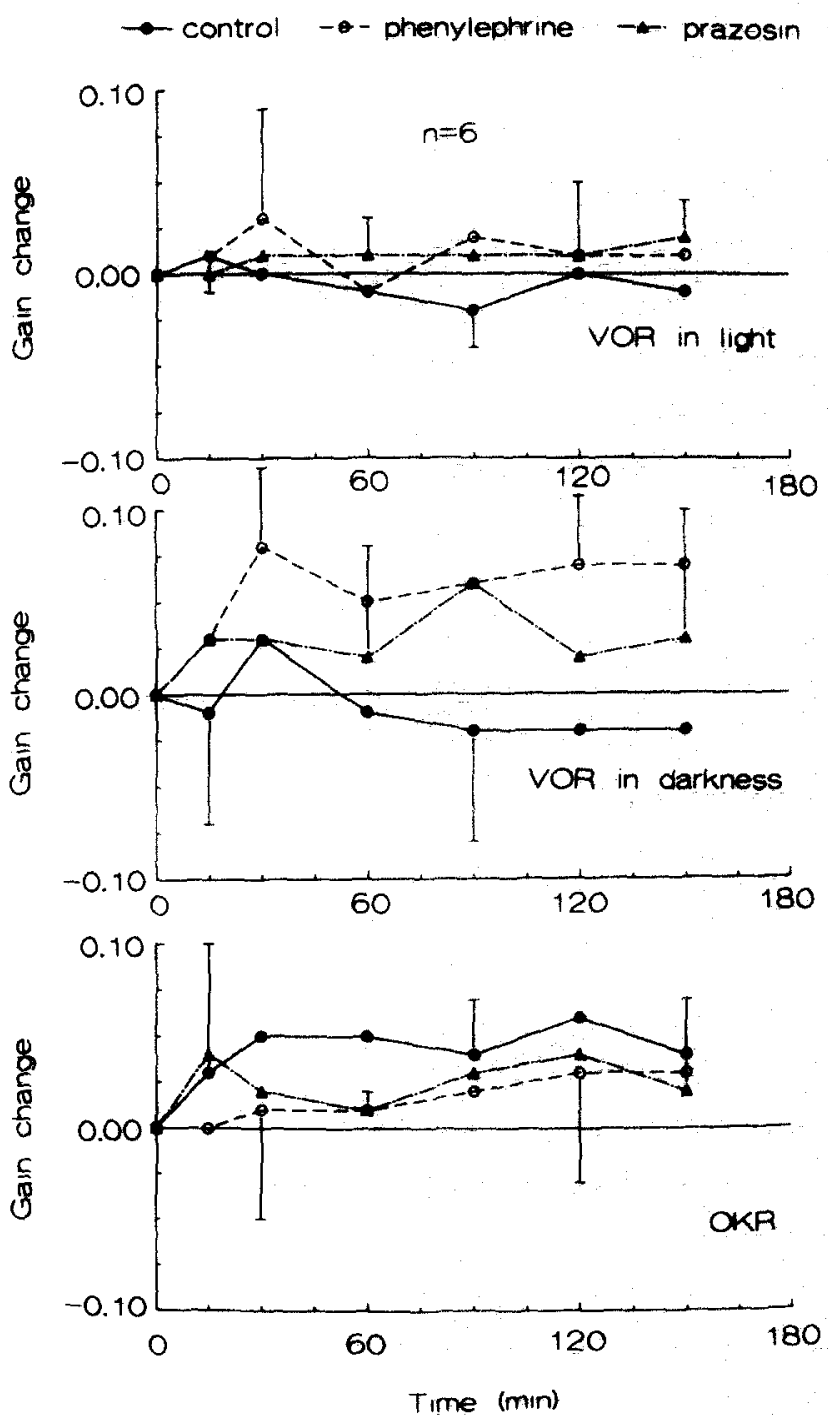

Fig. 7. Mean changes in gain of oculomotor responses as a function of time in control sessions and after bilateral floccular injection of phenylephrine or prazosin. under stimulus conditions not requiring any adaptation. 
$\alpha_{1}$-agents in flocculus

Adaptation experiments

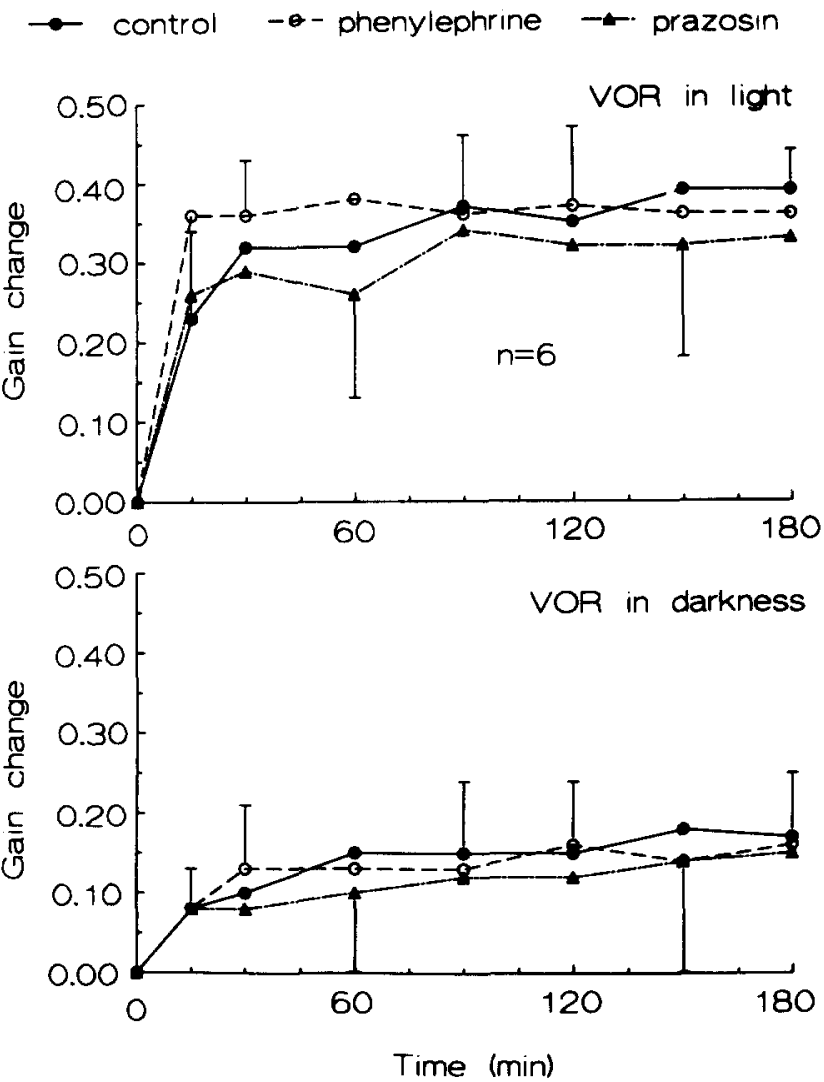

Fig. 8. Mean changes in gain of oculomotor responses during sessions requiring upward adaptation, under control conditions, and after bilateral floccular injection of phenylephrine or prazosin.

\section{Intrafloccular injections of $\alpha_{1}$-(ant)agonists}

Intrafloccular injection (in 6 rabbits) of the $\alpha_{1}$-agonist phenylephrine or the $\alpha_{1}$-antagonist prazosin did not significantly affect the basic gain of the VOR in light and in darkness or the OKR (Fig. 7).

The effects of intrafloccular microinjection of phenylephrine and prazosin were also examined under conditions that required upward adaptation of the gain of the VOR.

Fig. 8 shows the time course of the average increase in gain after injection of the $\alpha_{1}$-agonist and the $\alpha_{1}$-antagonist, compared to the control adaptation curve. Although Fig. 8 (upper panel) suggests an effect of the $\alpha_{1^{-}}$ agonist and antagonist early after the injection, no statistically significant effects were demonstrated in the multiple analysis of variance of the complete set of data. A similar absence of $\alpha_{1}$ effects was found for the VOR in darkness, as shown in Fig. 8, lower panel, and confirmed by multiple analysis of variance.

In summary, the adaptive stimulus resulted in a good enhancement of the gain of the VOR in light and in darkness. Floccular injection of an $\alpha_{1}$-noradrenergic ag- onist or antagonist affected neither the basic gains nor their adaptive changes.

\section{DISCUSSION}

In addition to $\beta$-adrenergic receptors, $\alpha_{1}$ - and $\alpha_{2}$-receptors have been encountered in the cerebellum ${ }^{3-5,17}$. 31.43. A specific role of $\beta$-receptors in noradrenergic actions on cerebellar unit activity has been shown before ${ }^{27}$. 47. Recently, Van Neerven et al. ${ }^{46}$ showed that floccular $\beta$-adrenergic receptor stimulation improves, and $\beta$-receptor blocking impairs adaptation of the VOR in the rabbit. The results of the present study suggest that, unlike the $\beta$-receptors, the floccular $\alpha$-receptors are not involved in adaptation of the VOR. Intrafloccular injections of the $\alpha_{1}$-agonist phenylephrine, the $\alpha_{1}$-blocker prazosin, the $\alpha_{2}$-agonist clonidine, and the $\alpha_{2}$-blocker idazoxan all failed to influence VOR adaptation. The effect of NA on VOR adaptation should thus be considered as mediated solely through $\beta$-adrenergic receptors. In addition, floccular $\alpha$-receptor stimulation or blocking did not affect the basic characteristics of the VOR and OKR; this result was similar to that obtained before for $\beta$-receptors ${ }^{4 h}$.

Systemic injection of phenylephrine in a high dosage also did not affect the basic characteristics of VOR or OKR. This negative result does not exclude a role of extrafloccular $\alpha_{1}$-receptors in the brain in controlling the gain of the VOR or OKR, because phenylephrine will not easily pass the blood-brain barrier. Local intracerebral application of phenylephrine at sites other than the flocculus, where $\alpha_{1}$-receptors are prominent, will have to be tried to solve this problem. The inferior olive, one of the structures most densely labeled for $\alpha_{1}$-receptors ${ }^{17}$ would seem to be a target of choice. Systemically administered clonidine, on the other hand, did have a marked effect on the basic characteristics of VOR and OKR. Although clonidine has peripheral effects on $\alpha_{2^{-}}$ receptors, causing vasoconstriction, the substance does pass the blood-brain barrier and has strong central activity $^{12}$. Intravenous injection of $0.07 \mathrm{mg} / \mathrm{kg}$ clonidine resulted in an immediate and sharp reduction in the gains of OKR and VOR in darkness, followed by a recovery of the gains of the two reflexes in less than half an hour. The time courses of the changes in gain were similar for the VOR and OKR. The gain of the VOR in light was not affected by this dosage. Apparently, the combined effect of VOR and OKR was strong enough to overcome the depressive effects on these reflexes acting alone. The gain reductions were dose-dependent, indicating that the effect was specific for clonidine. At the highest dose $(0.7$ $\mathrm{mg} / \mathrm{kg}$ ), the depression of OKR and VOR in darkness was equally profound as after $0.07 \mathrm{mg} / \mathrm{kg}$, but lasted 
much longer. In addition, the VOR in light was also mildly depressed (gain decreased by about 0.3 ) at the highest dose.

Systemic injection of clonidine may induce drowsiness or sedation in several species, including $\operatorname{man}^{23}$. Although, theoretically, the effects of clonidine on the VOR and OKR gains could be caused by such general changes in the animal's state, no obvious change in alertness and behavior was detected in our experiments after the injection of clonidine at any dosage. Also the appearance of frequent spontaneous saccades after the high dosage $(0.7 \mathrm{mg} / \mathrm{kg})$ of clonidine argues against drowsiness as an underlying cause.

It remains uncertain through which part of the brain clonidine influences the VOR and OKR gains. A large number of $\alpha_{2}$-receptors has been encountered in the $\mathrm{LC}^{36,43,52}$. Local or systematic application of clonidine into the $\mathrm{LC}$ results in a decrease in LC neuron firing rate, probably through auto-inhibition via $\alpha_{2}$-receptors located on LC neurons ${ }^{1,10,37,40}$.

The LC is the main source of NA in the brain ${ }^{41}$. A decrease in $L C$ neuron firing rate would thus result in a general reduction of the liberation of NA as a neurotransmitter in the central nervous system. However, this effect does not explain our results, as general depletion of central NA stores by 6-hydroxydopamine does not affect the basic gain of the VOR, although it impairs its adaptability $^{24}$. Thus, the effect of clonidine on the VOR and OKR is probably mediated postsynaptically by structures other than the LC. A plausible site of action would be the inferior olive, in which specific, although not very dense, labeling of $\alpha_{2}$-receptors has been shown ${ }^{9,36,43}$. Abolition of pharmacologically (harmaline + serotonin) induced rhythmic activity of inferior olivary neurons by noradrenaline has been found in guinea-pig brainstem

\section{REFERENCES}

1 Abercrombie, E.D. and Jacobs, B.L., Microinjected clonidine inhibits noradrenergic neurons of the locus coeruleus in freely moving cats, Neurosci. Lett., 76 (1987) 203-208.

2 Amaral, D.G. and Sinnamon, H.M., Locus coeruleus: neurobiology of a central noradrenergic nucleus, Prog. Neurobiol., 9 (1977) 147-196.

3 Boyajian, C.L., Loughlin, S.E. and Leslie, F.M., Anatomical evidence for alpha- 2 adrenoceptor heterogeneity: differential autoradiographic distributions of $\left[{ }^{3} \mathrm{H}\right]$ rauwolscine and $\left[{ }^{3} \mathrm{H}\right]$ idazoxan in rat brain, J. Pharmacol. Exp. Ther., 241 (1987) 10791091.

4 Brüning, G., Kaulen, P. and Baumgarten, H.G., Quantitative autoradiographic localization of $\alpha_{2}$-antagonist binding sites in rat brain using $\left[{ }^{3} \mathrm{H}\right]$ idazoxan, Neurosci. Lett., 83 (1987) 333 337.

5 Bylund, D.B. and U'Prichard, D.C., Characterization of $\alpha_{1}$ and $\alpha_{2}$-adrenergic receptors, Int. Rev. Neurobiol., 24 (1983) 343-431.

6 Collewijn, H., Eye- and head movements in freely moving rab- slices $^{22}$. Other possible sites are the medial vestibular nucleus, which has been mentioned in several reports as being labeled significantly by various $\alpha_{2}$-ligands ${ }^{3,8.43}$. and/or the pontine reticular formation. Both of these structures, as well as the inferior olive, are involved in the VOR and $\mathrm{OKR}^{35}$

A decrease in LC activity would also decrease the NA input to the flocculus. As adaptation of the VOR is found to be under influence of the $\beta$-component of the NA input to the flocculus ${ }^{46}$, systemic clonidine application can be expected to interfere with adaptation of the VOR. Such an effect, however, if present, would be masked by the negative effect that clonidine has on the basic gain characteristics, and would thus be difficult to demonstrate.

Our highest dose $(0.7 \mathrm{mg} / \mathrm{kg})$ of intravenous clonidine was followed by the appearance of frequent, spontaneous saccades, which are normally rare in rabbits with the head fixed ${ }^{7}$. A similar effect was revealed in humans in a catecholamine depletion study ${ }^{42}$. Metyrosin ( $\alpha$-methylparatyrosine), which temporarily depletes NA and dopamine, produced an increase in the amplitude and frequency of saccadic intrusions during fixation and pursuit. We may thus hypothesize that, in our case, the appearance of the saccades after clonidine injection was the result of a decrease in NA release in the brain, possibly caused by $\mathrm{LC}$ inhibition by clonidine.

Acknowledgements. This research was supported in part by the Netherlands Foundation for Medical Research MEDIGON (Grant 900-550-092, to H.C.), in part by NIH Grant NS 07685-22 (to O.P.) and by grants of the MURST and ASI, Rome, Italy (to O:P.). We thank Drs. J. Van der Steen (Department of Physiology) and Th. Stijnen (Department of Epidemiology and Biostatistics) for invaluable advice and assistance. Idazoxan was kindly provided by Reckitt and Colman, U.K

bits, J. Physiol., 266 (1977) 471-498

7 Collewijn, H., The Oculomotor System of the Rabbit and its Plasticity, Springer, Heidelberg, 1981, 240 pp.

8 Fernandez, A., Del Arco, C., Gonzales, A.M., Tolivia, J. and Pazos, A., Autoradiographic distribution of $a_{2}$-adrenoreceptors in chick brain, labeled with ${ }^{3}$ HUK 14304 , Eur. J. Neurosci., Suppl., 2 (1989) 121.

9 Flügge, G., Jurdzinski, A., Brandt, S. and Fuchs, E., Alpha2adrenergic binding sites in the medulta oblongata of tree shrews demonstrated by in vitro autoradiography: species related differences in comparison to the rat, J. Comp. Neurot., 297 (1990) 253-266.

10 Foote, S.L., Bloom, F.E. and Aston-Jones, G., Nucleus locus coeruleus: new evidence of anatomical and physiological specificity, Physiol. Rev., 63 (1983) 844-914.

11 Freedman, R., Hoffer, B.J., Puro, D. and Woodward, D.J. Noradrenaline modulation of the responses of the cerebellar Purkinje cell to afferent synaptic activity, Br. J. Pharmacol., 57 (1976) 603-605.

12 Gilman, A.G., Rall, T.W., Nies, A.S. and Taylor, P. (Eds.). Goodman and Gilman's The Pharmacological Basis of Thera- 
peutics, 8th Edn., Pergamon, New York, 1990, pp. 208-209.

13 Graf, W. Simpson, J.I. and Leonard, C.S., The spatial organization of visual messages to the flocculus of the rabbit's cerebellum. II. Complex and simple spike responses of Purkinje cells, J. Neurophysiol., 60 (1988) 2091-2121.

14 Ito, M., The Cerebellum and Neural Control, Raven, New York, $1984,580 \mathrm{pp}$.

15 Ito, M., Long-term depression, Annu. Rev. Neurosci., 12 (1989) $85-102$.

16 Ito, M., Jastreboff, P.J. and Miyashita, Y., Specific effects of unilateral lesions in the flocculus upon eye movements in albino rabbits, Exp. Brain Res., 45 (1982) 233-242.

17 Jones, L.S., Gauger, L.L. and Davis, J.N., Anatomy of brain $\alpha_{1}$-adrenergic receptors: in vitro autoradiography with $\left[{ }^{125} \mathrm{I}\right]$ HEAT, J. Comp. Neurol, 231 (1985) 190-208.

18 Kasamatsu, T., Norepinephrine hypothesis for visual cortical plasticity: thesis, antithesis, and recent development, Curr. Top. Dev. Biol., 21 (1987) 367-389.

19 Kasamatsu. T., Pettigrew, J.D. and Ary, M., Restoration of visual cortical plasticity by local microperfusion of norepinephrine, J. Comp. Neurol., 185 (1979) 163-182.

20 Keller. E.L. and Smith, M.J., Suppressed visual adaptation of the vestibulo-ocular reflex in catecholamine-depleted cats, Brain Research, 258 (1983) 323-327.

21 Kety, S.S., The biogenic amines in the central nervous system: their possible roles in arousal, cmotion, and learning. In F.O. Schmidt (Ed.), The Neurosciences: Second Study Program, Rockefeller University Press, New York, 1970, pp. 324-336.

22 Llinás, R. and Yarom, Y., Oscillatory properties of guinea-pig inferior olivary ncurones and their pharmacological modulation: an in vitro study, J. Physiol., 376 (1986) 163-182.

23 Makela, J.P. and Hilakivi, I.T., Evidence for the involvement of alpha-2 adrenoceptors in the sedation but not REM sleep inhibition by clonidine in the rat, Med. Biol., 64 (1986) 355-360.

24 McElligot, J.G. and Freedman, W., Vestibulo-ocular reflex adaptation in cats before and after depletion of norepinephrine, Exp. Brain Res., 69 (1988) 509-521.

25 Melvill Jones, G., Adaptive modulation of VOR parameters by vision. In A. Berthoz and G. Melvill Jones (Eds.), Adaptive Mechanisms in Gaze Control, Reviews of Oculomotor Research, Vol. 1, Elsevier, Amsterdam, 1985, pp. 21-50.

26 Moises, H.C., Burne, R.A. and Woodward, D.J., Modification of the visual response properties of cerebellar neurons by norepinephrine, Brain Research, 514 (1990) 259-275.

27 Moises, H.C. and Woodward, D.J., Potentiation of GABA inhibitory action in cerebellum by locus coeruleus stimulation, Brain Research, 182 (1980) 327-344.

28 Moises, H.C., Waterhouse, B.D. and Woodward, D.J., Locus coerulcus stimulation potentiates Purkinje cell responses to afferent input: the climbing fiber system. Brain Research, 222 (1981) 43-64.

29 Moises, H.C., Waterhouse, B.D. and Woodward, D.J., Locus coerulcus stimulation potentiates local inhibitory processes in rat cerebellum, Brain Res. Bull., 10 (1983) 795-804.

30 Nagao, S., Effect of vestibulocerebellar lesions upon dynamic characteristics and adaptation of vestibulo-ocular and optokinetic responses in pigmented rabbits, Exp. Brain Res., 53 (1983) $36-46$.

31 Palacios, J.M., Hoyer, D. and Cortés, R., $\alpha$,-Adrenoceptors in the mammalian brain: similar pharmacology but different distribution in rodents and primates, Brain Research, 419 (1987) 65-75.

32 Parfitt, K.D., Freedman, R. and Bickford-Wimer, P.C., Electrophysiological effects of locally applied noradrenergic agents at cerebellar Purkinje neurons: receptor specificity, Brain Research, 462 (1988) 242-251.

33 Pompeiano, O.. d'Ascanio, P., Horn. E. and Stampacchia, G., Effects of local injection of the $\alpha_{2}$-adrenergic agonist clonidine into the locus cocruleus complex on the gain of vestibulospinal and cervicospinal reflexes in decercbrate cats, Arch. Ital. Biol., 125 (1987) 225-269.

34 Pompeiano, O.. Horn. E. and d'Ascanio, P., Locus coeruleus and dorsal pontine reticular influences on the gain of vestibu- lospinal reflexes. In C.D. Barnes and O. Pompeinao (Eds.), Neurobiology of the Locus Coeruleus, Progress in Brain Research, Vol. 88, Elsevier, Amsterdam, 1991.

35 Precht, W., Anatomical and functional organisation of optokinetic pathways. In G. Lennerstrand, D.S. Zee and E.L. Keller (Eds.), Functional Basis of Ocular Motility Disorders, Pergamon, Oxford, 1982, pp. 291-302.

36 Probst, A., Cortés, R. and Palacios, J.M., Distribution of $\alpha_{2-}$ adrenergic reccptors in the human brain stem: an autoradiographic study using $\left[{ }^{3} \mathrm{H}\right] p$-aminoclonidine, Eur. J. Pharmacol., $106(1985) 477-488$

37 Reiner, P.B., Clonidine inhibits central noradrenergic neurons in unanesthetized cats, Eur. J. Pharmacol., 115 (1985) 249-257.

38 Robinson, D.A., Adaptive gain control of vestibulo-ocular reflex by the cerebellum, J. Neurophysiol., 39 (1976) 954-969.

39 Starke, K. and Altmann, K.P., Inhibition of adrenergic neurotransmission by clonidine: an action on prejunctional $\alpha$-receptors, Neuropharmacology, 12 (1973) 339-347.

40 Svensson, T.H., Bunney, B.S. and Aghajanian, G.K., Inhibition of both noradrenergic and serotonergic neurons in brain by the $\alpha$-adrenergic agonist clonidine, Brain Research, 92 (1975) 291-306.

41 Swanson, L.W. and Hartman, B.K., The central adrenergic system. An immunofluorescence study of the location of cell bodies and their efferent connections in the rat utilizing dopamine$\beta$-hydroxylase as a marker, J. Comp. Neurol., 163 (1975) 467506 .

42 Tychsen, L. and Sitaram, N., Catecholamine depletion produces irrepressible saccadic eye movements in normal humans, Ann. Neurol., 25 (1989) 444-449.

43 Unnerstall, J.R., Kopajtic, T.A. and Kuhar, M.J., Distribution of $\alpha_{2}$ agonist binding sites in the rat and human central nervous system: analysis of some functional, anatomic correlates of the pharmacologic effects of clonidine and related adrenergic agents, Brain Res. Rev., 7 (1984) 69-101.

44 U'Prichard, D.C., Yamamura, H.I. and Reisine, T.D., Characterization and differential in vivo regulation of brain adrenergic receptor subtypes, Adv. Biochem. Psychopharmacol., 21 (1980) 213-221.

45 Van Neerven, J., Pompeiano, O. and Collewijn, H., Depression of the vestibulo-ocular and optokinetic responses by intrafloccular microinjection of GABA-A and GABA-B agonists in the rabbit, Arch. Ital. Biol., 127 (1989) 243-263.

46 Van Neerven, J., Pompeiano, O., Collewijn, H. and Van der Steen, J., Injections of $\beta$-noradrenergic substances in the flocculus of rabbits affect adaptation of the VOR gain, Exp. Brain Res., 79 (1990) 249-260.

47 Waterhouse, B.D., Moises, H.C., Yeh, H.H. and Woodward, D.J., Norepinephrine enhancement of inhibitory synaptic mechanisms in cerebellum and cercbral cortex: mediation by beta adrenergic receptors, J. Pharmacol. Exp. Ther., 221 (1982) $495-506$.

48 Waterhouse, B.D., Scssler, F.M., Cheng, J.T., Woodward, J.D., Azizi, S.A. and Moises, H.C., New evidence for a gating action of norepinephrine in central neuronal circuits of mammalian brain, Brain Res. Bull., 21 (1988) 425-432.

49 Woodward, D.J., Moises, H.C., Waterhouse, B.D., Hoffer, B.J. and Freedman, R., Modulatory actions of norepinephrine in the central nervous system, Fed. Proc., 38 (1979) 2109-2116.

50 Woodward, D.J., Moises, H.C., Waterhouse, B.D., Yeh, M.M. and Chcun, J.E., The cerebellar norcpinephrine system: inhibition, modulation and gating. In C.D. Barnes and O. Pompeiano (Eds.), Neurobiology of the Locus Coeruleus. Progress in Brain Research, Vol. 88, Elsevier, Amsterdam, 1991.

51 Yeh, H.H. and Woodward, D.J., Beta-1 adrenergic receptors mediate noradrenergic facilitation of Purkinje cell responses to gamma-aminobutyric acid in cerebellum of rat, Neuropharmacology, 22 (1983) 629-639.

52 Young, W.S. and Kuhar, M.J., Noradrenergic $\alpha 1$ and $\alpha 2$ receptors: light microscopic autoradiographic localization, Proc. Natl. Acad. Sci. U.S.A., 77 (1980) 1696-1700. 